\title{
Inhaled iloprost is a potent acute pulmonary vasodilator in HIV-related severe pulmonary hypertension
}

\author{
H.A. Ghofrani, G. Friese, T. Discher, H. Olschewski, R.T. Schermuly, N. Weissmann, W. Seeger, \\ F. Grimminger, J. Lohmeyer
}

Inhaled iloprost is a potent acute pulmonary vasodilator in HIV-related severe pulmonary hypertension. H.A. Ghofrani, G. Friese, T. Discher, H. Olschewski, R.T. Schermuly, N. Weissmann, W. Seeger, F. Grimminger, J. Lohmeyer. (C) ERS Journals Ltd 2004.

ABSTRACT: As antiretroviral therapy has improved life expectancy in human immunodeficiency virus (HIV) infection, the life-limiting complication of HIV-related pulmonary hypertension has come into focus. Inhalation of the stable prostacyclin analogue iloprost is an effective treatment for various forms of precapillary pulmonary hypertension. The main objective of the present study was to evaluate the safety and efficacy of inhaled iloprost in HIV-related pulmonary hypertension.

In eight patients with severe pulmonary hypertension related to HIV infection, right heart and femoral artery catheterisation were performed. The acute effect of oxygen, inhaled nitric oxide and aerosolised iloprost was investigated. Four patients underwent long-term treatment with inhaled iloprost.

The rank order of pulmonary vasodilatory potency was iloprost $>\mathrm{NO}>\mathrm{O}_{2}$, with a maximum reduction (mean \pm SEM) in pulmonary vascular resistance of $30.6 \pm 3.1 \%$ $(p<0.001), 5.9 \pm 3.9 \%$ and $-\mathbf{0 . 6} \pm 3.9 \%$, respectively. Concomitantly, inhaled iloprost significantly increased the cardiac index and central venous oxygen saturation. Chronic treatment with inhaled iloprost tended to improve the 6 min walking distance and decreased pulmonary vascular resistance in all patients (although not significantly). No serious adverse events and no major interactions with the ongoing antiretroviral therapy were noted.

In conclusion, inhaled iloprost is a potent pulmonary vasodilator in human immune deficiency virus-related pulmonary hypertension. Future studies are warranted to confirm the encouraging long-term beneficial results observed in the present limited number of patients.

Eur Respir J 2004; 23: 321-326.
Dept of Internal Medicine, University Hospital, Justus Liebig University Giessen, Giessen, Germany.

Correspondence: H.A. Ghofrani

Dept of Internal Medicine

Klinikstraße 36

35392 Gießen

Germany

Fax: 496419942419

E-mail: ardeschir.ghofrani@innere.med. uni-giessen.de

Keywords: Acquired immune deficiency syndrome

human immunodeficiency virus

iloprost

inhalation

pulmonary hypertension

treatment

Received: May 262003

Accepted after revision: September 52003

This study was supported by the German Research Foundation (Collaborative Research Centre 547).
Severe pulmonary hypertension is a debilitating disease resulting in short life expectancy and often affecting young people [1]. The association between human immune deficiency virus (HIV) infection and increased risk of development of chronic pulmonary hypertension is well documented [2-4]. The mechanisms underlying this coincidence are, however, not yet established. Owing to the similarities between the pathology and clinical course of HIV-associated pulmonary hypertension and primary pulmonary hypertension (PPH), both entities (among others) belong to the same class of pulmonary arterial hypertension (PAH) according to the new World Health Organization (WHO) classification [5]. Treatment of HIV patients with antiretroviral therapy (ART) has dramatically improved the quality of life and life expectancy of these patients since the late 1990s [4, 6-8]. Owing to the better prognosis of ART-treated patients, severe pulmonary hypertension more commonly represents the life-limiting complication in these patients [9].

There is little to offer patients at the moment with regard to therapy of pulmonary hypertension in HIV. Analogous to $\mathrm{PPH}$, continuous intravenous administration of epoprostenol has been proposed for treatment of HIV-associated PAH [10]. This therapy is known to improve exercise capacity and survival in patients with PPH [11]. However, this approach can be hampered by serious infectious complications of the intravenous line, systemic side-effects due to the nonselectivity of the vasodilatory effect and the comparably high costs of the therapy. Inhalation of aerosolised iloprost, a longacting prostacyclin analogue, was recently shown to cause strong preferential pulmonary vasodilatation in both primary and secondary pulmonary hypertension $[12,13]$. Long-term use of nebulised iloprost was found to be beneficial in severe $\mathrm{PPH}$, even when associated with overt right heart failure [14-16]. The aim of the present study was to evaluate the safety and efficacy of inhaled iloprost in HIV-related PAH. Additionally, long-term iloprost therapy was investigated in four patients with stable HIV infection undergoing ART.

\section{Methods}

Eight patients (five females and three males) with severe pulmonary hypertension (mean pulmonary arterial pressure $>35 \mathrm{mmHg}$ ) were included in the study. All patients suffered from HIV infection and concomitantly from pulmonary arterial hypertension, as defined by the WHO world symposium 
on pulmonary hypertension held in Evian, France [5]. All patients were admitted to the University Hospital (Justus Liebig University Giessen, Giessen, Germany) for diagnosis and therapy of the underlying HIV infection and testing of pulmonary vasoreactivity with evaluation of therapeutic options. The major exclusion criteria were: pulmonary hypertension secondary to chronic obstructive pulmonary disease, pulmonary venous congestion, congenital heart disease, acute or chronic inflammatory lung disease, pregnancy or insufficient contraceptive measures, and previous treatment with prostanoids. The individual response rate to vasodilators, including inhaled nitric oxide, did not represent an inclusion or exclusion criterion.

The study protocol, requiring right heart and femoral artery catheterisation, was approved by the Justus Liebig University Giessen Ethics Committee, and each patient gave written informed consent. Vasodilator testing was carried out as follows, and, if necessary, patients received nasal oxygen throughout the entire test procedure in order to achieve an arterial oxygen saturation of $>88 \%$. Each patient underwent short-term NO inhalation, with the maximum vasodilatory response to this agent requiring $20-40$ parts per million NO. After haemodynamic parameters had returned to baseline levels, iloprost inhalation was performed using an ultrasonic nebuliser (Multisonic compact ${ }^{\mathrm{TM}}$; Otto Schill, Probstzella, Germany; mass median aerodynamic diameter $3.9 \mu \mathrm{m} ; 4 \mathrm{~min}$ inhalation period; total inhaled dose $2.8 \mu \mathrm{g}$ iloprost) [17]. Haemodynamic and gas exchange parameters were measured $5,15,30,60,90$ and $120 \mathrm{~min}$ after iloprost inhalation.

\section{Statistical analysis}

All data are presented as mean \pm SEM. For each parameter, the response to vasodilator treatment was considered significant if the $95 \%(\mathrm{p}<0.05), 99 \%(\mathrm{p}<0.01)$ or $99.9 \%$ $(\mathrm{p}<0.001)$ confidence interval compared to pretreatment values did not overlap with zero. The Kruskal-Wallis test was used to determine a difference in haemodynamic responsiveness to the applied vasodilators.

\section{Results}

\section{Patient characteristics and concomitant medication}

Baseline haemodynamic parameter values are given in table 1, consistently showing severe pulmonary arterial hypertension and low cardiac indices. Left ventricular impairment was excluded by means of echocardiography and this is additionally documented by the low wedge pressures in each patient. Patient characteristics, including ongoing medication, are listed in table 2.

\section{Vasodilator testing during right heart catheterisation}

Nasal oxygen. Oxygen supply resulted in a significant increase in arterial oxygen tension $\left(\mathrm{Pa}_{2} \mathrm{O}_{2} ; 9.12 \pm 2.50 \mathrm{kPa}(46.0 \pm\right.$ $18.8 \mathrm{mmHg}), \mathrm{p}<0.05)$ and mixed venous oxygen saturation $(8.4 \pm 2.9 \%, p<0.01)$ (fig. 1). Despite some reduction in pulmonary arterial pressure, pulmonary vascular resistance (PVR) did not change. This was mainly attributed to a significant reduction in cardiac output $(4.1 \pm 1.6 \%, \mathrm{p}<0.01)$ (fig. 1$)$.

Nitric oxide inhalation. NO inhalation did not influence pulmonary or systemic haemodynamics significantly. No alteration in gas exchange was noted (fig. 1).

Iloprost inhalation. Inhalation of iloprost reduced PVR by $30.6 \pm 3.1 \% \quad(\mathrm{p}<0.001)$ and increased the cardiac index by $20.9 \pm 8.9 \%(\mathrm{p}<0.01)$ (fig. 1). The decrease in the PVR/systemic vascular resistance (SVR) ratio indicated preferential pulmonary vasodilatation. Central venous oxygen saturation increased significantly, whereas the $\mathrm{Pa}, \mathrm{O}_{2}$ remained unchanged. The iloprost effects levelled off within 120 min after nebulisation, as demonstrated for PVR in figure 2.

Chronic therapy with iloprost inhalation. Of the eight patients, four agreed to undergo chronic therapy with inhaled iloprost (6-9 inhalations $\left.\cdot \mathrm{day}^{-1}\right)$. All patients were treated with oral anticoagulants for $\geqslant 3$ months before inclusion in the study and this medication was continued during long-term treatment with iloprost. None of the patients were treated with digoxin. The dosage of diuretics (in all cases, a combination of spironolactone with furosemide) was unchanged during the observation period. In all of these patients, no significant changes in parameters of HIV infection were detectable during the course of chronic iloprost therapy (CD4 cell densities in patients 1-4 were 748 (702 after 6 months), 710 (680), 266 (320) and 820 (835) cells $\mu \mathrm{L}^{-1}$; HIV ribonucleic acid (RNA) levels remained below the detection limit in three of the four cases, and were changed from 300 copies $\cdot \mathrm{mL}^{-1}$ before treatment in patient No. 3 to below the detection limit after the 6-month observation period). Two patients classified in New York Heart Association Functional Class IV at baseline improved to Class III, and two patients previously in Class III improved to Class II, after 6 months of chronic iloprost therapy. All patients were satisfied with iloprost therapy. On average, the 6 min walking distance at baseline was $331 \pm 21 \mathrm{~m}$. Over a treatment period of 6 months, the walking distance increased to $417 \pm 40 \mathrm{~m}(\mathrm{p}=0.063$, Wilcoxon signed-rank test $)$ in these

Table 1.-Demographic, haemodynamic and gas exchange characteristics of individual patients at baseline

\begin{tabular}{|c|c|c|c|c|c|c|c|c|c|c|c|c|}
\hline $\begin{array}{l}\text { Patient } \\
\text { No. }\end{array}$ & $\begin{array}{l}\text { Age } \\
\text { yrs }\end{array}$ & Sex & $\begin{array}{l}\text { Height } \\
\mathrm{cm}\end{array}$ & $\begin{array}{l}\text { Weight } \\
\text { kg }\end{array}$ & $\begin{array}{c}\text { Mean } P \text { pa } \\
\text { mmHg }\end{array}$ & $\begin{array}{c}\text { PVR } \\
\text { dyn } \cdot \mathrm{s} \cdot \mathrm{cm}^{-5}\end{array}$ & $\stackrel{\mathrm{CI}}{\mathrm{L} \cdot \mathrm{min}^{-1} \cdot \mathrm{m}^{-2}}$ & $\begin{array}{c}P \mathrm{cv} \\
\mathrm{mmHg}\end{array}$ & $\begin{array}{c}P \text { paw } \\
\text { mmHg }\end{array}$ & $\underset{\mathrm{Sv}, \mathrm{O}_{2}}{\%}$ & $\begin{array}{l}\mathrm{Pa}, \mathrm{O}_{2} \\
\mathrm{mmHg}\end{array}$ & NYHAFC \\
\hline 1 & 31 & Female & 160 & 62 & 40 & 1618 & 1.08 & 3 & 4 & 45.2 & 87 & III \\
\hline 2 & 29 & Female & 168 & 43 & 49 & 2222 & 1.11 & 23 & 4 & 37.8 & 97 & IV \\
\hline 3 & 41 & Female & 167 & 52 & 48 & 924 & 2.25 & 3 & 7 & 54.1 & 42 & IV \\
\hline 4 & 41 & Female & 162 & 64 & 40 & 843 & 2.09 & 4 & 6 & 59.2 & 63 & III \\
\hline 5 & 34 & Male & 179 & 62 & 44 & 787 & 2.40 & 4 & 2 & 51.3 & 73 & III \\
\hline 6 & 51 & Male & 172 & 70 & 45 & 625 & 2.87 & 0 & 4 & 70.9 & 75 & III \\
\hline 7 & 43 & Male & 176 & 73 & 39 & 472 & 3.14 & 1 & 4 & 62.4 & 66 & III \\
\hline 8 & 36 & Female & 162 & 61 & 45 & 783 & 2.34 & 12 & 5 & 52.2 & 71 & III \\
\hline
\end{tabular}

Ppa: pulmonary arterial pressure; PVR: pulmonary vascular resistance; CI: cardiac index; $P$ cv: central venous pressure; $P$ paw: pulmonary arterial wedge pressure; $\mathrm{S}_{\mathrm{v}} \mathrm{O}_{2}$ : mixed venous oxygen saturation; $\mathrm{Pa}, \mathrm{O}_{2}$ : arterial oxygen tension; NYHAFC: New York Heart Association Functional Class. Patients 1-4 underwent long-term treatment with inhaled iloprost. $1 \mathrm{mmHg}=0.133 \mathrm{kPa} ; 1 \mathrm{dyn} \cdot \mathrm{cm}^{-2}=0.1 \mathrm{~Pa}$. 
patients (fig. 3). Baseline PVR was $1,402 \pm 324 \mathrm{dyn} \cdot \mathrm{s} \cdot \mathrm{cm}^{-5}$ $\left(1 \mathrm{dyn} \cdot \mathrm{cm}^{-2}=0.1 \mathrm{~Pa}\right)$. After 6 months of continued inhalational iloprost therapy, it decreased to $772 \pm 89 \mathrm{dyn} \cdot \mathrm{s} \cdot \mathrm{cm}^{-5}(\mathrm{p}=0.065)$ (fig. 3).

\section{Discussion}

In the present study, inhalation of iloprost, a stable analogue of prostacyclin, markedly reduced PVR and increased cardiac output in patients with severe pulmonary hypertension related to HIV infection. Long-term administration of aerosolised iloprost improved exercise capacity and pulmonary haemodynamics.

All patients except one had been receiving long-term ART for $\geqslant 2$ yrs before being tested in the present study. Stable T-helper (CD4) cell counts and HIV RNA levels indicated stability of the underlying disease. All were closely monitored in the University Hospital HIV outpatient clinic. Changes in ART were only made for HIV-related reasons. Severe pulmonary hypertension was noted in all patients. This was reflected by strongly elevated baseline pulmonary arterial pressures as well as low cardiac indices and low central venous oxygen saturation (table 1). Diagnostic procedures, including elaborate imaging techniques, excluded other causes of pulmonary hypertension from HIV infection (e.g. thromboembolic disease, cardiac shunting, connective tissue disease, hepatic cirrhosis, etc.). Currently, little is known about the pathogenesis and natural course of HIV-associated pulmonary hypertension. However, life expectancy is dramatically reduced (irrespective of CD4 cell counts) compared to the mean survival of HIV-infected patients treated with ART as soon as manifest pulmonary hypertension is detectable [4, 9, 18, 19].

Application of nasal oxygen significantly increased arterial oxygenation and mixed venous oxygen saturation without inducing major changes in arterial or systemic haemodynamics. This indicates that hypoxic vasoconstriction, due to reduced $\mathrm{Pa}, \mathrm{O}_{2}$, is not a major contributor to the pulmonary hypertension in these patients. The moderate decrease in pulmonary arterial pressure was paralleled by a minor, though significant, decrease in cardiac output and frequency, with PVR unchanged. Most probably, this reflects some reduction in the sympathetic drive due to adequate arterial oxygenation.

Inhaled $\mathrm{NO}$ is a selective pulmonary vasodilator in different types of acute and chronic pulmonary hypertension $[20,21]$. Pharmacological challenge with this agent during right heart catheterisation is widely accepted as a screening tool that helps identify patients who will respond favourably to long-term treatment with high doses of oral calcium channel blockers [22]. A PVR reduction of $\geqslant 30 \%$ during NO inhalation is generally regarded as reflecting substantial vasoresponsiveness [21]. In the present study, no patient was found to be a "NO-responder". In contrast to NO, inhaled iloprost caused a significant decrease in PVR, accompanied by a decrease in pulmonary arterial pressure and a substantial increase in cardiac output and central venous oxygen saturation. Together, this reflects improved oxygen delivery in these patients. Moreover, the decrease in the PVR/SVR ratio indicates preferential pulmonary as compared to systemic vasodilation, in response to the inhaled prostanoid. This observation, showing that inhaled iloprost is a more potent pulmonary vasodilator than NO in different types of pulmonary hypertension, is in accordance with previous findings from both the present authors' group and other investigators $[12,23]$.

Intravenous epoprostenol is an effective and life-saving therapy in PPH [11]. Recent reports have been suggestive of a 

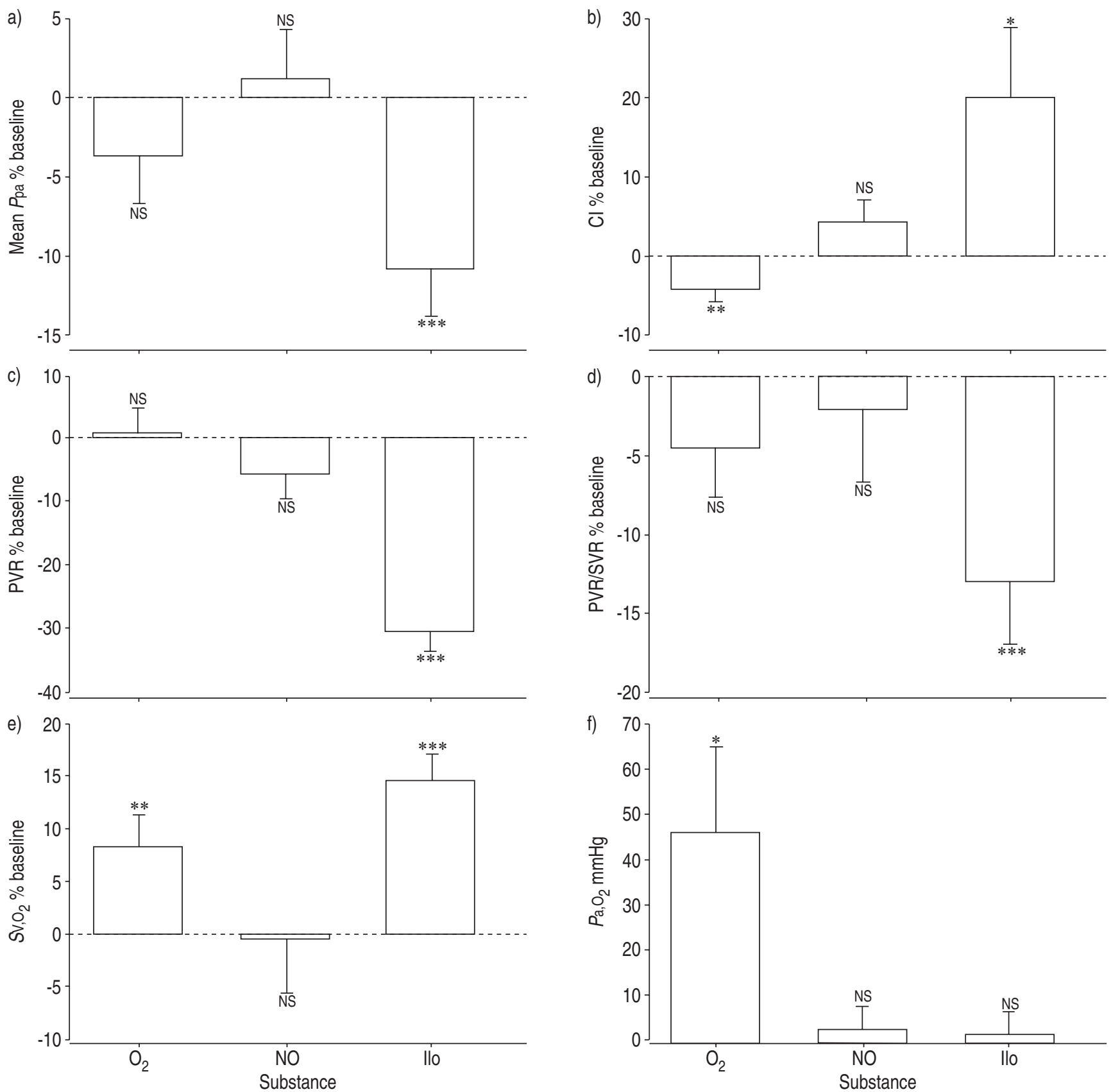

Fig. 1. - Haemodynamic and gas exchange responses to oxygen $\left(\mathrm{O}_{2}\right)$, inhaled nitric oxide (NO) and inhaled iloprost (Ilo) (p-values for intergroup differences are given in parenthesis): a) mean pulmonary arterial pressure $(P \mathrm{pa} ; \mathrm{p}=0.04) ; \mathrm{b})$ cardiac index $(\mathrm{CI} ; \mathrm{p}=0.009)$; c) pulmonary vascular resistance (PVR; $\mathrm{p}=0.0001)$; $) \mathrm{PVR} /$ systemic vascular resistance (SVR) ratio $(\mathrm{p}=0.23)$; e) mixed venous oxygen saturation $\left(S_{\mathrm{v}}, \mathrm{O}_{2} ; \mathrm{p}=0.01\right)$; and $\mathrm{f}$ ) arterial oxygen tension $\left(\mathrm{Pa}_{\mathrm{a}} \mathrm{O}_{2} ; \mathrm{p}=0.03\right)$. Data are presented as mean $\pm \mathrm{SEM}$ and the maximum deviations from baseline are shown. $* * * * * *$ : $\mathrm{p}<0.05, \mathrm{p}<0.01, \mathrm{p}<0.001$ versus baseline (Kruskal-Wallis test). NS: nonsignificant. $1 \mathrm{mmHg}=0.133 \mathrm{kPa}$.

potential role for this therapy in HIV-related pulmonary hypertension [9, 10, 14]. The data of NunES et al. [9] demonstrate that the use of a combination of ART and epoprostenol infusion is related to better survival in patients with severe HIV-associated pulmonary hypertension, and, therefore, might be considered one therapeutic option in this patient group. However, the use of intravenous epoprostenol can be associated with at least three limiting drawbacks. First, the lack of pulmonary selectivity of the vasodilatory effect results in systemic side-effects. Secondly, development of tolerance may make progressive dosage increase necessary. Thirdly, serious infections may occur via the intravenous delivery line [24]. Application of prostanoids via inhalation is an appealing concept for circumventing most of these shortcomings of infusion therapy [12]. Indeed, chronic inhalation of iloprost was shown to be an effective and well-tolerated therapy for PPH and some forms of nonprimary pulmonary hypertension in a recent multicentric trial [25]. In the present investigation, four patients received longterm inhaled iloprost therapy on a compassionate treatment basis. As shown in previous studies, this type of prostanoid therapy was well tolerated, no serious adverse events were reported and all patients were satisfied with iloprost therapy. Moreover, exercise capacity (6 min walking distance) 


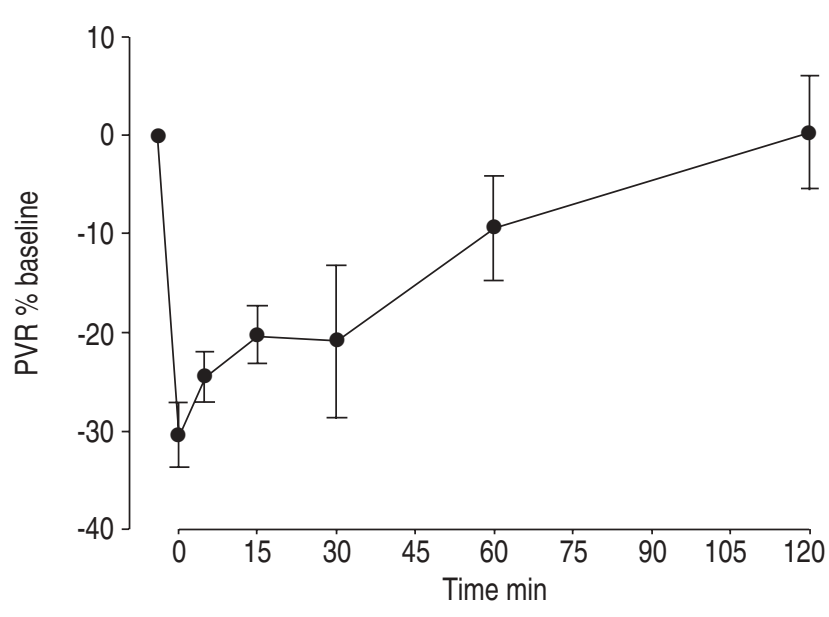

Fig. 2. - Time course of pulmonary vascular resistance (PVR) decrease in response to iloprost inhalation. The reduction in PVR after a single 4-min inhalation of $2.8 \mu \mathrm{g}$ iloprost over the subsequent $120 \mathrm{~min}$ is shown. Data are presented as mean \pm SEM

increased and PVR decreased in all patients over a 6-month observation period. Although uncontrolled, these consistent changes strongly suggest efficacy of iloprost in HIV-associated pulmonary hypertension. In addition to this nonparenteral therapeutic approach, new oral treatments are currently under investigation for several forms of chronic
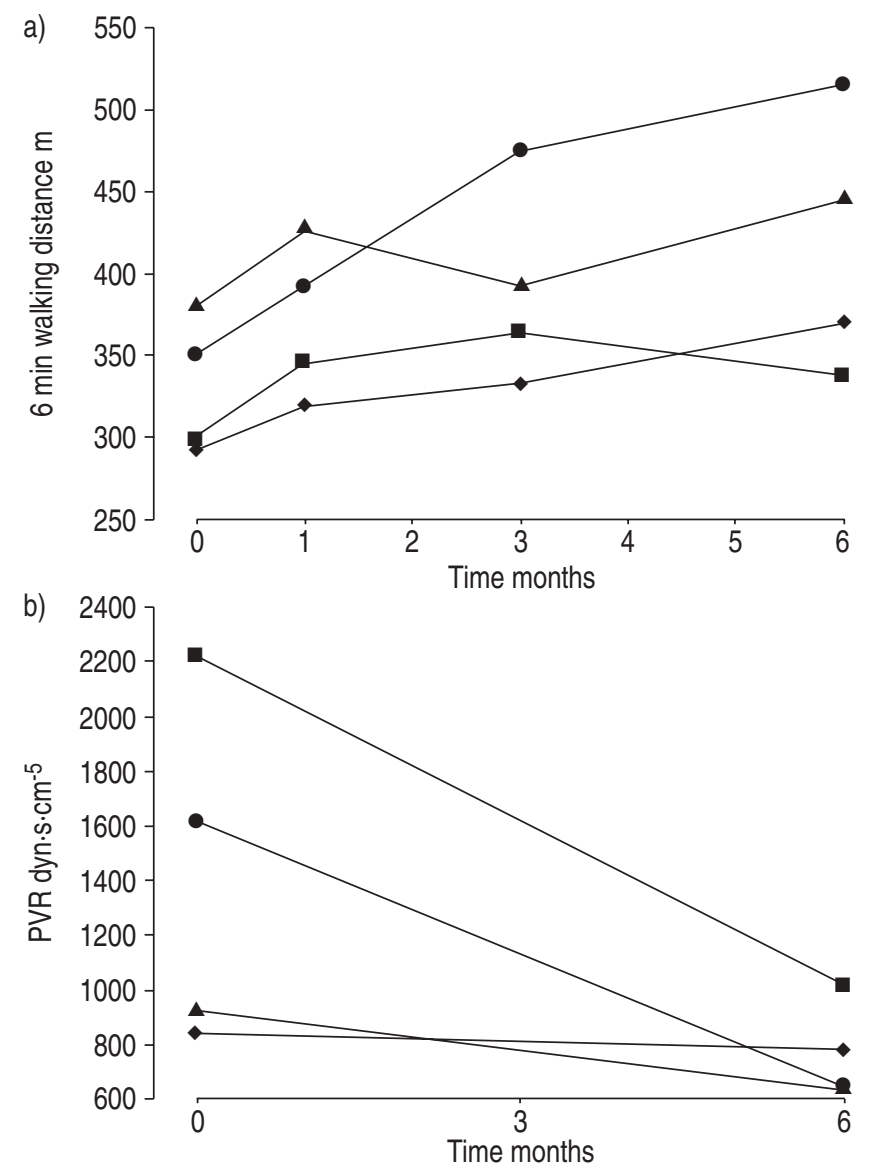

Fig. 3.-Long-term follow up of: a) 6 min walking distance; and b) pulmonary vascular resistance (PVR) under therapy with daily repetitive iloprost inhalation. Each patient is represented by a different symbol. $1 \mathrm{dyn} \cdot \mathrm{cm}^{-2}=0.1 \mathrm{~Pa}$. pulmonary hypertension. The endothelin receptor antagonist bosentan is already of proven efficacy in the treatment of PAH [26]. However, to date, no data have been published about its use in patients with HIV and pulmonary hypertension. In the European phase III trial with oral beraprost, in addition to the majority of patients who had PAH (including those with PPH and pulmonary hypertension associated with collagen vascular disease), a few patients with HIV-associated pulmonary hypertension were included [27]. In this study in particular, the subgroup of patients with PPH showed beneficial clinical effects. Recently, the successful use of the oral phosphodiesterase 5 inhibitor sildenafil has been reported in a small series of patients with HIV-associated pulmonary hypertension [28].

In conclusion, inhaled iloprost showed pulmonary vasodilatory potency in patients with human immunodeficiency virus infection-related pulmonary hypertension. Patients treated long-term with the aerosolised prostanoid might show improvements in exercise capacity and pulmonary haemodynamics. These encouraging observations, obtained in a limited number of patients, warrant further controlled studies on iloprost inhalation for the treatment of human immunodeficiency virus-associated pulmonary hypertension.

Acknowledgements. The authors are grateful to J. Yeager for thorough linguistic editing of the manuscript.

\section{References}

1. Rubin LJ. Primary pulmonary hypertension. $N$ Engl J Med 1997; 336: 111-117.

2. Mette SA, Palevsky HI, Pietra GG, et al. Primary pulmonary hypertension in association with human immunodeficiency virus infection. A possible viral etiology for some forms of hypertensive pulmonary arteriopathy. Am Rev Respir Dis 1992; 145: 1196-1200.

3. Petitpretz P, Brenot F, Azarian R, et al. Pulmonary hypertension in patients with human immunodeficiency virus infection. Comparison with primary pulmonary hypertension. Circulation 1994; 89: 2722-2727.

4. Opravil M, Pechere M, Speich R, et al. HIV-associated primary pulmonary hypertension. A case control study. Swiss HIV Cohort Study. Am J Respir Crit Care Med 1997; 155: 990-995.

5. Rich S, ed. Primary Pulmonary Hypertension. Executive Summary from the World Symposium on Primary Pulmonary Hypertension 1998, Evian, France, 6-10 September 1998. www.who.int/cardiovascular_diseases/resources/publications/en/ Date accessed: 10 November 2003.

6. Cooper DA. Immunological effects of antiretroviral therapy. Antivir Ther 1998; 3: Suppl. 4, 19-23.

7. Bower M, Fox P, Fife K, Gill J, Nelson M, Gazzard B. Highly active anti-retroviral therapy (HAART) prolongs time to treatment failure in Kaposi's sarcoma. AIDS 1999; 13: 2105-2111.

8. McNaghten AD, Hanson DL, Jones JL, Dworkin MS, Ward JW. Effects of antiretroviral therapy and opportunistic illness primary chemoprophylaxis on survival after AIDS diagnosis. Adult/Adolescent Spectrum of Disease Group. AIDS 1999; 13: 1687-1695.

9. Nunes H, Humbert M, Sitbon O, et al. Prognostic factors for survival in human immunodeficiency virus-associated pulmonary arterial hypertension. Am J Respir Crit Care Med 2003; 167: 1433-1439.

10. Aguilar RV, Farber HW. Epoprostenol (prostacyclin) therapy in HIV-associated pulmonary hypertension. Am J Respir Crit Care Med 2000; 162: 1846-1850.

11. Barst RJ, Rubin LJ, Long WA, et al. A comparison of continuous intravenous epoprostenol (prostacyclin) with 
conventional therapy for primary pulmonary hypertension. The Primary Pulmonary Hypertension Study Group. $N$ Engl J Med 1996; 334: 296-302.

12. Olschewski H, Walmrath D, Schermuly R, Ghofrani A, Grimminger F, Seeger W. Aerosolized prostacyclin and iloprost in severe pulmonary hypertension. Ann Intern Med 1996; 124: 820-824.

13. Olschewski H, Ghofrani HA, Schmehl $\mathrm{T}$, et al. Inhaled iloprost to treat severe pulmonary hypertension. An uncontrolled trial. German PPH Study Group. Ann Intern Med 2000; 132: 435-443.

14. Stricker H, Domenighetti G, Fiori G, Mombelli G. Sustained improvement of performance and haemodynamics with long-term aerosolised prostacyclin therapy in severe pulmonary hypertension. Schweiz Med Wochenschr 1999; 129: 923-927.

15. Hoeper MM, Schwarze M, Ehlerding S, et al. Long-term treatment of primary pulmonary hypertension with aerosolized iloprost, a prostacyclin analogue. $N$ Engl J Med 2000; 342: 1866-1870.

16. Beghetti $\mathrm{M}$, Berner $\mathrm{M}$, Rimensberger PC. Long term inhalation of iloprost in a child with primary pulmonary hypertension: an alternative to continuous infusion. Heart 2001; 86: E10.

17. Gessler T, Schmehl T, Hoeper MM, et al. Ultrasonic versus jet nebulization of iloprost in severe pulmonary hypertension. Eur Respir J 2001; 17: 14-19.

18. Speich R, Jenni R, Opravil M, Pfab M, Russi EW. Primary pulmonary hypertension in HIV infection. Chest 1991; 100: 1268-1271.

19. Mehta NJ, Khan IA, Mehta RN, Sepkowitz DA. HIVrelated pulmonary hypertension: analytic review of 131 cases. Chest 2000; 118: 1133-1141.

20. Rossaint R, Falke KJ, Lopez F, Slama K, Pison U, Zapol
WM. Inhaled nitric oxide for the adult respiratory distress syndrome. $N$ Engl J Med 1993; 328: 399-405.

21. Sitbon O, Brenot F, Denjean A, et al. Inhaled nitric oxide as a screening vasodilator agent in primary pulmonary hypertension. A dose-response study and comparison with prostacyclin. Am J Respir Crit Care Med 1995; 151: 384 389.

22. Sitbon O, Humbert M, Jagot JL, et al. Inhaled nitric oxide as a screening agent for safely identifying responders to oral calcium-channel blockers in primary pulmonary hypertension. Eur Respir J 1998; 12: 265-270.

23. Hoeper MM, Olschewski H, Ghofrani HA, et al. A comparison of the acute hemodynamic effects of inhaled nitric oxide and aerosolized iloprost in primary pulmonary hypertension. German PPH study group. J Am Coll Cardiol 2000; 35: 176-182.

24. Barst RJ, Rubin LJ, McGoon MD, Caldwell EJ, Long WA, Levy PS. Survival in primary pulmonary hypertension with long-term continuous intravenous prostacyclin. Ann Intern Med 1994; 121: 409-415.

25. Olschewski H, Simonneau G, Galie N, et al. Inhaled iloprost for severe pulmonary hypertension. N Engl J Med 2002; 347 322-329.

26. Rubin LJ, Badesch DB, Barst RJ, et al. Bosentan therapy for pulmonary arterial hypertension. $N$ Engl J Med 2002; 346: 896-903.

27. Galie N, Humbert M, Vachiery JL, et al. Effects of beraprost sodium, an oral prostacyclin analogue, in patients with pulmonary arterial hypertension: a randomized, doubleblind, placebo-controlled trial. J Am Coll Cardiol 2002; 39: 1496-1502.

28. Schumacher YO, Zdebik A, Huonker M, Kreisel W. Sildenafil in HIV-related pulmonary hypertension. AIDS 2001; 15: 1747-1748. 